\title{
Diagnostic precision and identification of rare diseases is dependent on distance of residence relative to tertiary medical facilities
}

\author{
Kantonsspital Sankt Gallen \\ Florent Baty \\ Kantonsspital Sankt Gallen \\ Frank Rassouli \\ Kantonsspital Sankt Gallen \\ Stefan Bilz \\ Kantonsspital Sankt Gallen \\ Martin Hugo Brutsche \\ Kantonsspital Sankt Gallen
}

Anna-Lena Walter ( $\sim$ Anna-Lena.Walter@kssg.ch )

Research

Keywords: rare diseases, diagnostic diversity, distance to center

Posted Date: July 17th, 2020

DOI: https://doi.org/10.21203/rs.3.rs-41736/v1

License: (9) This work is licensed under a Creative Commons Attribution 4.0 International License. Read Full License

Version of Record: A version of this preprint was published on March 22nd, 2021. See the published version at https://doi.org/10.1186/s13023-021-01769-6. 


\section{Abstract}

Background Diagnostic precision and the identification of rare diseases (RDs) is a daily challenge, which needs specialized expertise. We hypothesized, that there is a correlation between the distance of residence to the next tertiary medical facility with specialized care and the diagnostic precision, especially for rare diseases.

Results We found a negative association between diagnostic diversity and travel time to the next tertiary hospital when including all cases throughout the overall International Classification of Diseases version 10 (ICD-10) diagnosis codes. This was paralleled with a negative association of standardized incidence rates in all groups of rare diseases except for rare teratologic and rare allergic diseases. The effect started at travel times of $>21$ minutes.

Conclusion Our findings indicate towards a higher risk of being mis-, under- or late diagnosed especially in rare diseases when living more distant to a tertiary medical facility. Greater distance to the next tertiary medical facility basically increases the chance for hospitalization in a non-comprehensive regional hospital with less diagnostic capacity, and, thus, impacts on adapted health care access. Therefore, solutions for overcoming the distance to specialized care as an indicator of health care access are a major goal in the future.

\section{Background}

More than 20 years ago the European Union (EU) identified rare diseases, defined as life-threatening or chronically debilitating conditions affecting not more than 5/10'000 persons in the community(1), as a significant problem regarding expertise, research and development of medications(2) as they were often diagnosed late(3-5), misdiagnosed or not diagnosed at all(6). Although each rare disease only affects a relatively small number of patients and families, taken as a whole they represent a serious burden for health care systems worldwide. The need to bring together expertise and make efficient use of the limited available resources means that rare diseases are an area where cooperation between health care regions can add particular value(6). Specialized centers are therefore needed as a critical factor for assuring the quality of medical care in this group of patients. The accessibility of those centers is crucial, as shown for different rare conditions $(7,8)$, but also for diseases such as cancer(9), common respiratory diseases like asthma or chronic obstructive pulmonary disease (COPD)(10) as well as cardiovascular(11) and neurological diseases(12). This accessibility of medical care depends on different determinants, which include geographic, regulatory and socio-economic factors $(13,14)$ and vary depending on the health care set-up. Geographic dispersion also impacts on the management of patients. It is well known that the distance to the next hospital is arbitrative in emergencies, especially in respiratory emergencies(15) and acute myocardial infarction(11). Krohn et. al. showed that geographic dispersion leads to decreased rates of hospital discharge and a higher rate of discharge to skilled nursing facilities(16). We hypothesized that diagnostic precision, measured by the diagnostic diversity index (DDI) as a reproducible quality indicator of tho diannnctin nraricinn af innationt naro depending on the caseload of the hospital(17), is affected by Loading [MathJax]/jax/output/CommonHTML/jax.js 
spatial disparities along the geographical dispersion of specialized medical centers. The aim of the current project was therefore, to examine whether there is a correlation between the mean diagnostic diversity and standardized incidence rates for rare diseases from inpatient cases of residents from a particular area and their travel time to the next tertiary inpatient facility.

\section{Results}

A total of 5'390'591 inpatient cases from 2009 to 2012 were included. In these cases 17'751 different ICD-10 codes were used. Per case a median of 3 coded diagnoses (interquartile range $1-5$ ) were observed. Figure 1 shows the distribution of the number of diagnoses. Rare diseases were coded in 1'464'753/5'390'591 (27\%) of inpatient cases.

\section{Association between travel time and diagnostic diversity}

Overall, based on all inpatient cases and using all ICD-10 codes, there was a significant inverse association following a sigmoid shape between the diagnostic diversity and the travel time between the area of residence and the closest tertiary inpatient facility (Fig. 2A-C). The effects substantiate for travel times $>21$ minutes, which was identified as the time where the tangent passing through the inflection point is crossing the upper asymptote.

\section{Association between travel time and incidence rate of rare diseases}

In order to investigate whether the above-mentioned observation of a negative association between diagnostic diversity and travel time was on the expenses of rare diseases, we restricted our analysis on rare diseases as defined by Orphanet. With this, we found a significant inverse sigmoid-shaped association between standardized incidence rates and travel time from residence to the closest tertiary inpatient facility (Fig. 2D). When analyzing rare diseases group by group the effect was present for all groups of rare diseases except for rare teratologic and rare allergic diseases (Fig. 3).

\section{Discussion}

According to our study a longer travel time between residence and the next tertiary medical center is associated with less diagnostic diversity, i.e. precision, and a lower chance of being diagnosed with a rare disease- most likely due to varying accessibility to suitable health care resources even in a welleconomized country like Switzerland. The effect is particularly pronounced in patients with rare diseases, where standardized incidence rates for several orphan disease groups fell below $50 \%$ at travel times of > 60 minutes to the next tertiary health center. Although 20-60 minutes travel time seems to be irrelevant in comparison to other countries. But the 39 centers are accompanied by 242 other inpatient facilities(18).

Standardized incidence rates of all different groups of rare diseases were affected except for teratologic 
malformation syndromes, which are rather obvious to detect. Rare allergic diseases primarily refer to many different reasons of angioedema and urticaria, which as well are visual, and, thus, less missed diagnoses regardless of the cause(19). The term "rare diseases" is misleading as rare diseases are listed as main or co-diagnoses in more than 1 in 4 hospitalizations in our study. Of the 6'172 rare diseases listed by Orphanet, $84.5 \%$ have a prevalence of $<1 / 1^{\prime} 000^{\prime} 000$. Nguengang et al. assume that the prevalence of rare diseases is at least 3.5-5.9\%, meaning 18-30 million persons in the EU, 263446 million persons worldwide(20). Thus, our findings point to a relevant as well as prevalent structural issue of health care accessibility in relation to geographical dispersion and might indicate a higher risk of being mis-, under- or late diagnosed in more remote residential areas. This is especially important for those rare diseases which appear accentuated in rural areas of residence as sarcoidosis(21). Underdiagnoses or diagnostic delay has been shown to have negative impact on the course of the disease in many rare diseases(6). In idiopathic pulmonary fibrosis early treatment can slow down disease progression and therefore the decline in lung function(22). Those low prevalence diseases with unspecific symptoms as interstitial lung diseases (cough, dyspnea) are explicitly in danger to have a diagnostic delay $(3,23)$. In Glucose transporter-1 deficiency syndrome ketogenic diet reduces the frequency of seizures and severity of motoric impairment(24). Early treatment in patients with Hurler Syndrome (mucopolysaccharidosis type 1) prevents cognitive or physical disability(25). So an early and precise diagnosis is crucial. Of course this fact is also well known in acute cardiovascular and neurological situations, but also in oncological diseases with negative impact due to therapeutic delay(26-28).

There are different possible strategies to overcome the "distance-to-center" challenge. The obvious option is to optimize health care location planning using geographic information systems, average travel distance to the next clinic site and electronic health records, as Soares et al. investigated in the United States of America (USA)(29). Such an approach allows for a proactive planning of health care infrastructure optimizing for accessibility as well as sufficient caseload. This is well known for complex surgical interventions, as well as for some emergency conditions and low-risk procedures in Germany(30). But also diagnostic performance is strongly associated with caseload(17). In contrast to a high number of smaller hospitals with limited diagnostic capabilities, a smaller number of high-volume inpatient facilities can offer a comprehensive access to subspecialities. Tele-health care will also probably gain even more importance in the future. Tele-health care is defined as a complex intervention, with information from patients being electronically transferred over a distance to health care professionals, who analyze this information and give immediate and personalized feedback and advice to the patient(31) via telephone or internet. Electronic consultations (e-consults) "offer a rapid, direct, and documented communication pathway for consultation between primary care and specialist"(32). Muse et al. provided an interactive platform for physicians to discuss complex cases on an international base, which found favor especially with younger medical practitioners. 37,706 physicians from 171 countries on every continent used the platform during the 2 years duration of this study(33). As tele-health care promises to be available anywhere and anytime, it could optimize health care access independent of the geographic and socio-cultural dispersion. Furthermore there are diagnostic decision support systems (DnSSc) availahle tn accesc "race data hased on incorporated medical knowledge, compiling lists of Loading [MathJax]/jax/output/CommonHTML/jax.js

Page 4/13 
differential diagnoses appropriate for a given sample of evidence"(34). McGowan et al. used a just-intime librarian consultation system with a highly positive impact in decision making in primary care(35). Electronic online-services developed by Orphanet and by other EU-funded projects are claimed to contribute to put patients in contact with other patients and develop patient communities, to share databases between research groups, to collect data for clinical research, to register patients willing to participate in clinical research, and to submit cases to experts which improve the quality of diagnoses and treatment(6). European registries are thought to be an important column of quality of care in rare diseases. Collaborative networks between centers and smaller institutions could be another option to handle the distance-to-center problem.

\section{Limitations}

The quality of medical coding - although professionalized in all institutions - might be limited and varying between institutions. The ICD-10 coding doesn't represent the majority of rare diseases adequately, so there will be an expansion of the number of specific codes in ICD-11(36). The latter is going to come into force on 1st of January 2022(37). The database does not allow accounting for differences in socio-economic status between cases or regions. Another limitation is that only inpatient cases are documented in the available data. Also, we concentrated on individual motorized transport times and didn't include transfer times by public means of transport. Ambulances might transport patients more likely within cantonal borders than to the actual nearest hospital. As Switzerland is a rather small country with a total area of 41,285 square kilometers(38), the longest distance to cover in our cohort was approximately $250 \mathrm{~km}$. The regional differences in health care quality in larger countries are likely even more relevant depending on the distances to the next center. Of course, besides geographic disparities there are other factors influencing access to healthcare, e.g. socio-economic status. Last, pediatric hospitals are not included in the list of tertiary centers as they are not considered as general care institutions and represent an own group of 3 hospitals in Switzerland(18).

\section{Conclusion}

The diagnostic diversity as a marker of diagnostic precision of inpatient cases was inversely related to travel time from home to the next tertiary inpatient facility - a marker for health care accessibility. The effect reached significance starting at travel times $>21$ minutes and was even more pronounced at times $>43$ minutes, where the diagnostic diversity dropped by $>50 \%$. The effect was particularly true for rare diseases, where standardized incidence rates dropped $>50 \%$ at travel times $>60$ minutes to the next tertiary inpatient facility. Rare diseases seem to be more likely under-, mis- and late diagnosed in individuals living more distant to a tertiary medical facility. A greater distance to the next tertiary medical facility basically increases the chance for a hospitalization in a non-comprehensive regional hospital with less diagnostic capacity, and, thus, impacts on adapted health care access. Thus we provide new evidence-based arguments for a proactive planning of health care infrastructure. Remote residential 
areas should receive more specialized medical support, e.g., through collaborative networks and/or telehealth strategies.

\section{Methods}

We used a database provided by the Swiss Federal Office for Statistics offering a nation-wide coverage of all hospitalization cases between 2009 and 2015 (9.325.326 hospitalization cases). For each hospitalization case, the data set included one main diagnosis as well as up to 50 additional diagnoses, coded using the International Classification of Diseases version 10 (ICD-10-GM) codes. The data set also included the patients' area of residence, separated into 705 "Medstat" regions defined by the postal codes by MicroGIS. The distance and travel time between each region and the closest center hospital were obtained using the finaroute webtool(39). Travel time was calculated for individual motorized transportation. The Swiss Federal Office of Health (BAG) defined 44 centers in Switzerland, including 5 university hospitals and 39 large hospitals, which are mostly cantonal hospitals(18). The definition of a center is based on the caseload of inpatient care and advanced training categories(40).

Regarding rare diseases we used the definition of Orphanet, a 37-country network, co-funded by the European Commission that aims to increase knowledge on RDs so as to improve the diagnosis, care, and treatment of people with RDs. In total, 6'172 diseases(41), malformation syndromes, morphological, and biological anomalies, as well as particular clinical situations are considered as 'rare in Europe'(20), meaning a prevalence of 5/10.000 or less. They are divided into 35 groups(42). In order to link the rare diseases listed by Orphanet and the cases recorded in the hospitalization database, the alignment between rare disease codes (ORPHAnumber) and ICD-10 codes provided by Orphanet was used. This cross-referencing provides an assignment of ICD-10 codes to each ORPHAnumber(43). Those codes of RDs within these 35 groups were taken forward for analyses.

\section{Statistical considerations}

The diversity of diagnoses was calculated using the Shannon diversity index defined as follows:

$$
H=-\sum_{i=1}^{D} p_{i} \ln \left(p_{i}\right)
$$

with $\mathrm{D}$ the number of diagnoses (ICD-10 codes) and $p_{i}$ the proportional abundance of the $i^{\text {th }}$ diagnosis. Further details can be found in our previous publication(17).

The relationship between the diagnostic diversity and the travel time to the closest tertiary institution was investigated using nonlinear regression. A 4-parameter log-logistic regression was fitted and the time where the tangent passing through the inflection point is crossing the upper asymptote was estimated.

In disease mapping as a sub-type of spatial analysis, standardized incidence rate is used as a measure of relative risk. The standardized incidence rate of the rare diseases in the different Swiss regions was 
estimated. The relationship between the standardized incidence rate and the travel time to closest tertiary institution was modeled using Poisson regression.

All analyses were done using the R statistical software(44) including the extension package "drc" for nonlinear regression(45).

\section{Declarations}

\section{Ethics approval and consent to participate:}

Ethical approval was not required for our retrospective analysis of anonymized data. No written informed consent was given to the patients who were unidentifiable due to the anonymization.

\section{Consent for publication:}

Not applicable (see above)

\section{Availability of data and materials:}

The Swiss Federal Office for Statistics only provides regulated access to the data for research purpose.

\section{Competing interests:}

All authors declare they have no competing interests

\section{Funding:}

The study was supported by an unconditional research grant by the Lung League St. Gallen - Appenzell and an institutional grant by the Cantonal Hospital St. Gallen.

\section{Author's contribution:}

ALW wrote the manuscript, FB performed the statistical analysis, FR and MB supervised the work and participated to the writing of the manuscript, SB provided his expertise in the field of rare diseases.

\section{Acknowledgments:}

We are thankful to Mrs. Kei Kozu who helped retrieving the distances and times from the Medstat regions to the tertiary inpatient facilities.

\section{References}

1. Smith R, Regulation (EC) No 764/2008 of the European Parliament and of the Council. Core EU Legislation [Internet]. London: Macmillan Education UK; 2015 [zitiert 15. Juni 2020]. S. 183-6. Verfügbar unter: http://link.springer.com/10.1007/978-1-137-54482-7_19.

2. Union PO of the E. CELEX1. Decision No 1295/1999/EC of the European Parliament and of the Loading [MathJax]/jax/output/CommonHTML/jax.js gramme of Community action on rare diseases within the 
framework for action in the field of public health (1999 to 2003) [Internet]. 1999 [zitiert 15. Juni 2020]. Verfügbar unter: http://op.europa.eu/en/publication-detail/-/publication/208111e4-414e4da5-94c1-852f1c74f351/language-en.

3. Hoyer N, Prior TS, Bendstrup E, Wilcke T, Shaker SB. Risk factors for diagnostic delay in idiopathic pulmonary fibrosis. Respir Res Dezember. 2019;20(1):103.

4. Bhattacharya K, Balasubramaniam S, Choy YS, Fietz M, Fu A, Jin DK. u. a. Overcoming the barriers to diagnosis of Morquio A syndrome. Orphanet J Rare Dis Dezember. 2014;9(1):192.

5. Seymour B. Primary antibody deficiency and diagnostic delay. J Clin Pathol 1 Mai. 2005;58(5):5467.

6. rare_com_en.pdf [Internet]. [zitiert 15. Juni 2020]. Verfügbar unter: https://ec.europa.eu/health/ph_threats/non_com/docs/rare_com_en.pdf.

7. Merker VL, Dai A, Radtke HB, Knight P, Jordan JT, Plotkin SR. Increasing access to specialty care for rare diseases: a case study using a foundation sponsored clinic network for patients with neurofibromatosis 1, neurofibromatosis 2, and schwannomatosis. BMC Health Serv Res Dezember. 2018;18(1):668.

8. Schieppati A, Henter J-I, Daina E, Aperia A. Why rare diseases are an important medical and social issue. The Lancet Juni. 2008;371(9629):2039-41.

9. Lin CC, Bruinooge SS, Kirkwood MK, Olsen C, Jemal A, Bajorin D. u. a. Association Between Geographic Access to Cancer Care, Insurance, and Receipt of Chemotherapy: Geographic Distribution of Oncologists and Travel Distance. J Clin Oncol 1 Oktober. 2015;33(28):3177-85.

10. Beran D, Zar HJ, Perrin C, Menezes AM, Burney P. Burden of asthma and chronic obstructive pulmonary disease and access to essential medicines in low-income and middle-income countries. Lancet Respir Med Februar. 2015;3(2):159-70.

11. 10.1161/JAHA. 115.002378

Balamurugan A, Delongchamp R, Im L, Bates J, Mehta JL. Neighborhood and Acute Myocardial Infarction Mortality as Related to the Driving Time to Percutaneous Coronary Intervention-Capable Hospital. J Am Heart Assoc [Internet]. 23. Februar 2016 [zitiert 2. Juni 2020];5(2). Verfügbar unter: https://www.ahajournals.org/doi/10.1161/JAHA.115.002378.

12. Saver JL, Fonarow GC, Smith EE, Reeves MJ, Grau-Sepulveda MV, Pan W. u. a. Time to Treatment With Intravenous Tissue Plasminogen Activator and Outcome From Acute Ischemic Stroke. JAMA 19 Juni. 2013;309(23):2480.

13. Sequist TD. Ensuring Equal Access to Specialty Care. N Engl J Med 9 Juni. 2011;364(23):2258-9.

14. Forrest CB, Nutting PA, von Schrader S, Rohde C, Starfield B. Primary Care Physician Specialty Referral Decision Making: Patient, Physician, and Health Care System Determinants. Med Decis Making Januar. 2006;26(1):76-85.

15. Nicholl J, West J, Goodacre S, Turner J. The relationship between distance to hospital and patient mortality in emergencies: an observational study. Emerg Med J 1 September. 2007;24(9):665-8. 
16. Kohn R, Harhay MO, Weissman GE, Anesi GL, Bayes B, Song H. u. a. The Association of Geographic Dispersion with Outcomes among Hospitalized Pulmonary Service Patients. Ann Am Thorac Soc Februar. 2020;17(2):249-52.

17. Brutsche M, Rassouli F, Gallion H, Kalra S, Roger VL, Baty F. Diagnostic diversity - an indicator of institutional and regional healthcare quality. Swiss Med Wkly. 2018;03:148:w14691.

18. kzp18_publication.pdf. [Internet]. [zitiert 15. Juni 2020]. Verfügbar unter: https://spitalstatistik.bagapps.ch/data/download/kzp18_publication.pdf?v=1591328549.

19. Rare Diseases [Internet]. [zitiert 15. Juni 2020]. Verfügbar unter: http://www.orphadata.org/cgibin/rare_free.html.

20. Nguengang Wakap S, Lambert DM, Olry A, Rodwell C, Gueydan C, Lanneau V. u. a. Estimating cumulative point prevalence of rare diseases: analysis of the Orphanet database. Eur J Hum Genet Februar. 2020;28(2):165-73.

21. Deubelbeiss U, Gemperli A, Schindler C, Baty F, Brutsche MH. Prevalence of sarcoidosis in Switzerland is associated with environmental factors. Eur Respir J 1 Mai. 2010;35(5):1088-97.

22. Aiello M, Bertorelli G, Bocchino M, Chetta A, Fiore-Donati A, Fois A. u. a. The earlier, the better: Impact of early diagnosis on clinical outcome in idiopathic pulmonary fibrosis. Pulm Pharmacol Ther Juni. 2017;44:7-15.

23. Pritchard D, Adegunsoye A, Lafond E, Pugashetti JV, DiGeronimo R, Boctor N. u. a. Diagnostic test interpretation and referral delay in patients with interstitial lung disease. Respir Res Dezember. 2019;20(1):253.

24. Leen WG, Klepper J, Verbeek MM, Leferink M, Hofste T, van Engelen. BG, u. a. Glucose transporter-1 deficiency syndrome: the expanding clinical and genetic spectrum of a treatable disorder. Brain 1 März. 2010;133(3):655-70.

25. Eisengart JB, Rudser KD, Xue Y, Orchard P, Miller W, Lund T. u. a. Long-term outcomes of systemic therapies for Hurler syndrome: an international multicenter comparison. Genet Med November. 2018;20(11):1423-9.

26. Herlitz J, WireklintSundström B, Bång A, Berglund A, Svensson L, Blomstrand C. Early identification and delay to treatment in myocardial infarction and stroke: differences and similarities. Scand J Trauma Resusc Emerg Med. 2010;18(1):48.

27. Bleicher RJ. Timing and Delays in Breast Cancer Evaluation and Treatment. Ann Surg Oncol Oktober. 2018;25(10):2829-38.

28. Gomez DR, Liao K-P, Swisher SG, Blumenschein GR, Erasmus JJ, Buchholz TA. u. a. Time to treatment as a quality metric in lung cancer: Staging studies, time to treatment, and patient survival. Radiother Oncol Mai. 2015;115(2):257-63.

29. Soares N, Dewalle J, Marsh B. Utilizing patient geographic information system data to plan telemedicine service locations. J Am Med Inform Assoc September. 2017;24(5):891-6.

30. Nimptsch U, Mansky T. Hospital volume and mortality for 25 types of inpatient treatment in German Loading [MathJax]/jax/output/CommonHTML/jax.js mplete national data from 2009 to 2014. BMJ Open 
September. 2017;7(9):e016184.

31. McLean S, Nurmatov U, Liu JL, Pagliari C, Car J, Sheikh A. Telehealthcare for chronic obstructive pulmonary disease. Cochrane Airways Group, Herausgeber. Cochrane Database Syst Rev [Internet]. 6. Juli 2011 [zitiert 2. Juni 2020]; Verfügbar unter: http://doi.wiley.com/10.1002/14651858.CD007718.pub2.

32. Vimalananda VG, Gupte G, Seraj SM, Orlander J, Berlowitz D, Fincke BG. u. a. Electronic consultations (e-consults) to improve access to specialty care: A systematic review and narrative synthesis. $J$ Telemed Telecare September. 2015;21(6):323-30.

33. Muse ED, Godino JG, Netting JF, Alexander JF, Moran HJ, Topol EJ. From second to hundredth opinion in medicine: A global consultation platform for physicians. Npj Digit Med Dezember. 2018;1(1):55.

34. Ronicke S, Hirsch MC, Türk E, Larionov K, Tientcheu D, Wagner AD. Can a decision support system accelerate rare disease diagnosis? Evaluating the potential impact of Ada DX in a retrospective study. Orphanet J Rare Dis Dezember. 2019;14(1):69.

35. McGowan J, Hogg W, Campbell C, Rowan M. Just-in-Time Information Improved Decision-Making in Primary Care: A Randomized Controlled Trial. Hales S, Herausgeber. PLoS ONE 21 November. 2008;3(11):e3785.

36. Montserrat A, Taruscio D. Policies and actions to tackle rare diseases at European level. Ann Ist Super Sanita September. 2019;55(3):296-304.

37. Wann kommt die ICD-11? [Internet]. [zitiert 15. Juni 2020]. Verfügbar unter: https://www.dimdi.de/dynamic/de/faq/faq/Wann-kommt-die-ICD-11/.

38. Snapshot [Internet]. [zitiert 15. Juni 2020]. Verfügbar unter:

https://www.eda.admin.ch/aboutswitzerland/de/home/umwelt/geografie/geografie--fakten-undzahlen.html.

39. Finaroute. Arlesheim BL - Villeneuve VD [Internet]. [zitiert 30. Juni 2020]. Verfügbar unter: http://www.danielwaech.ch/cgi-bin/finaroute.

40. Statistik der stationären Betriebe.pdf.

41. Orphanet [Internet]. [zitiert 15. Juni 2020]. Verfügbar unter: https://www.orpha.net/consor/cgibin/index.php.

42. Rare Diseases [Internet]. [zitiert 15. Juni 2020]. Verfügbar unter: http://www.orphadata.org/cgibin/rare_free.html.

43. ORPHAnomenclature [Internet]. [zitiert 8. Juli 2020]. Verfügbar unter: http://www.orphadata.org/cgibin/ORPHAnomenclature.html.

44. R Core Team. (2016). R: A language and environment for statistical computing. R Foundation for Statistical Computing, Vienna, Austria. [Internet]. Verfügbar unter: https://www.R-project.org/.

45. Muggeo V. Segmented: An R Package to Fit Regression Models With Broken-Line Relationships. R News 1 Januar. 2008:8:20-5. 
Figures

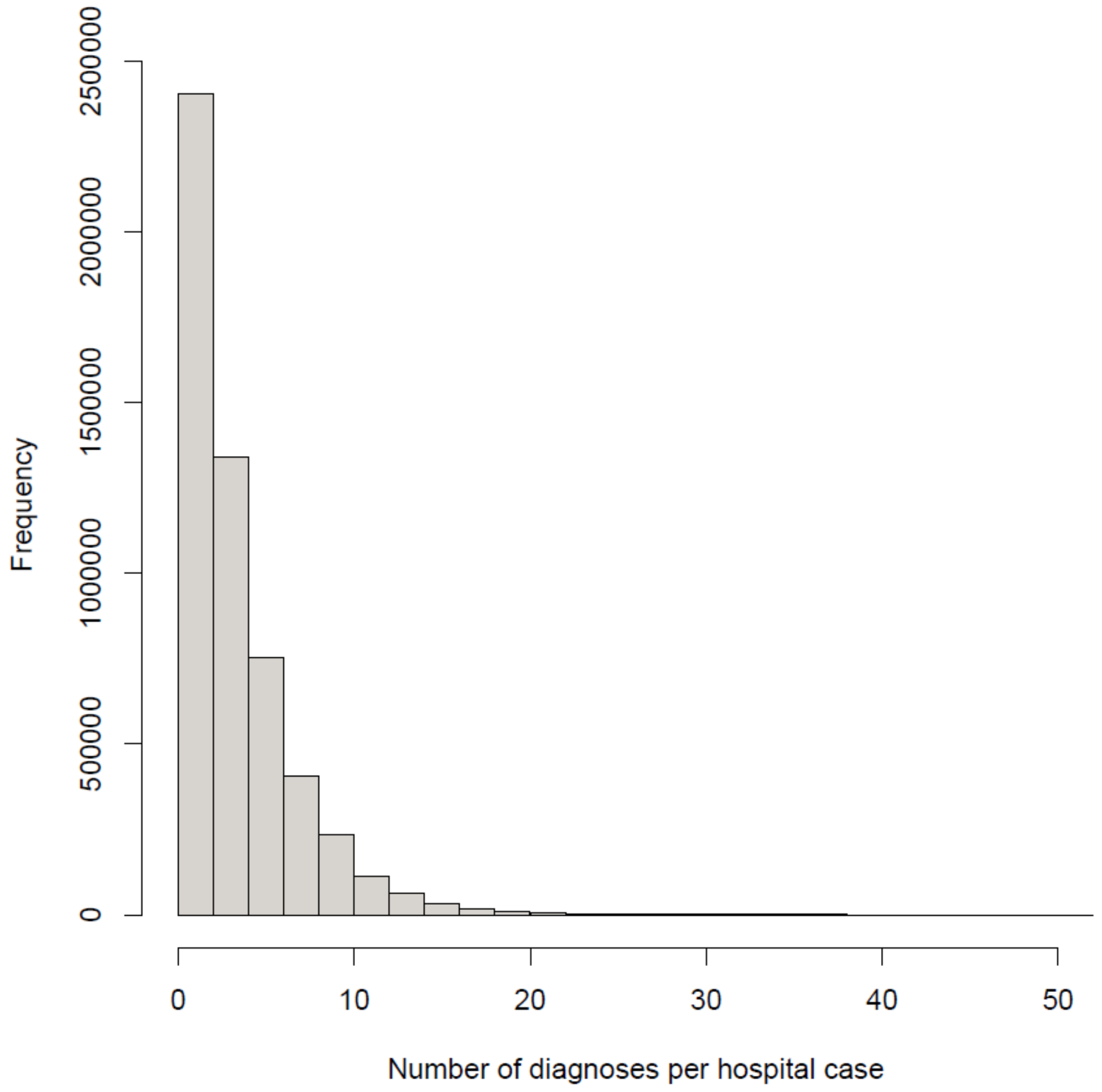

Figure 1

Distribution of the number of diagnoses. 
A

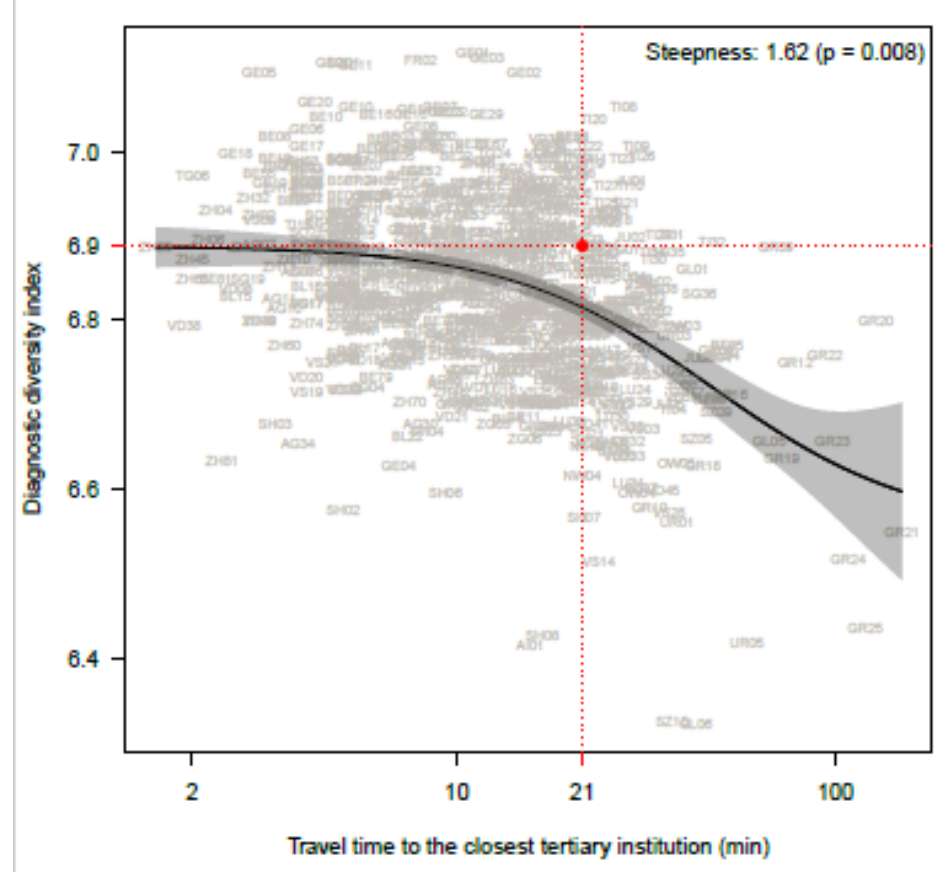

C
ㅁ $\leq 21 \mathrm{~min}$

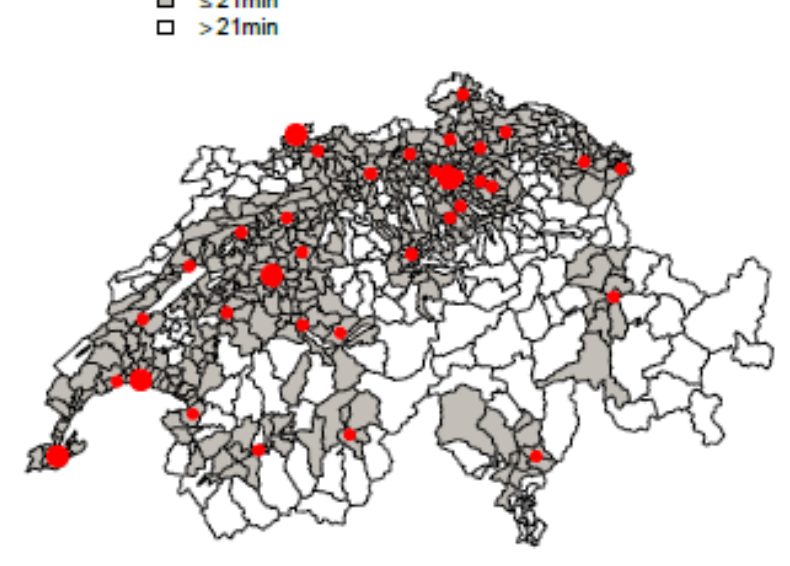

Travel time to the closest tertiary institution
B
Diagnostic diversity index

$\square>6.9$

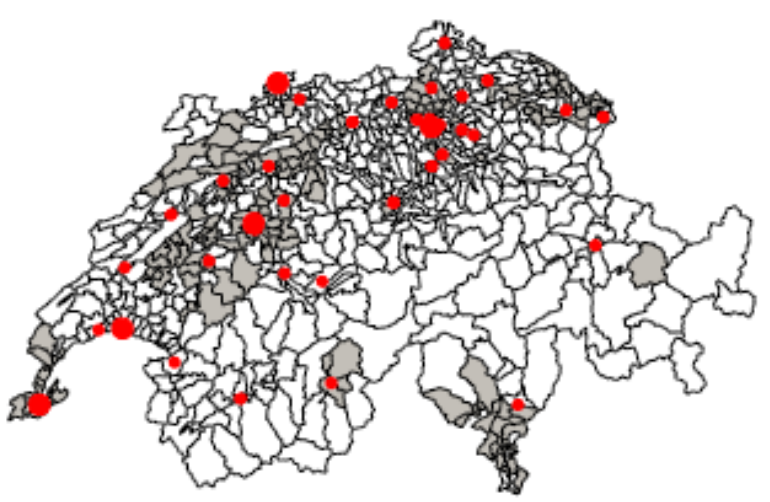

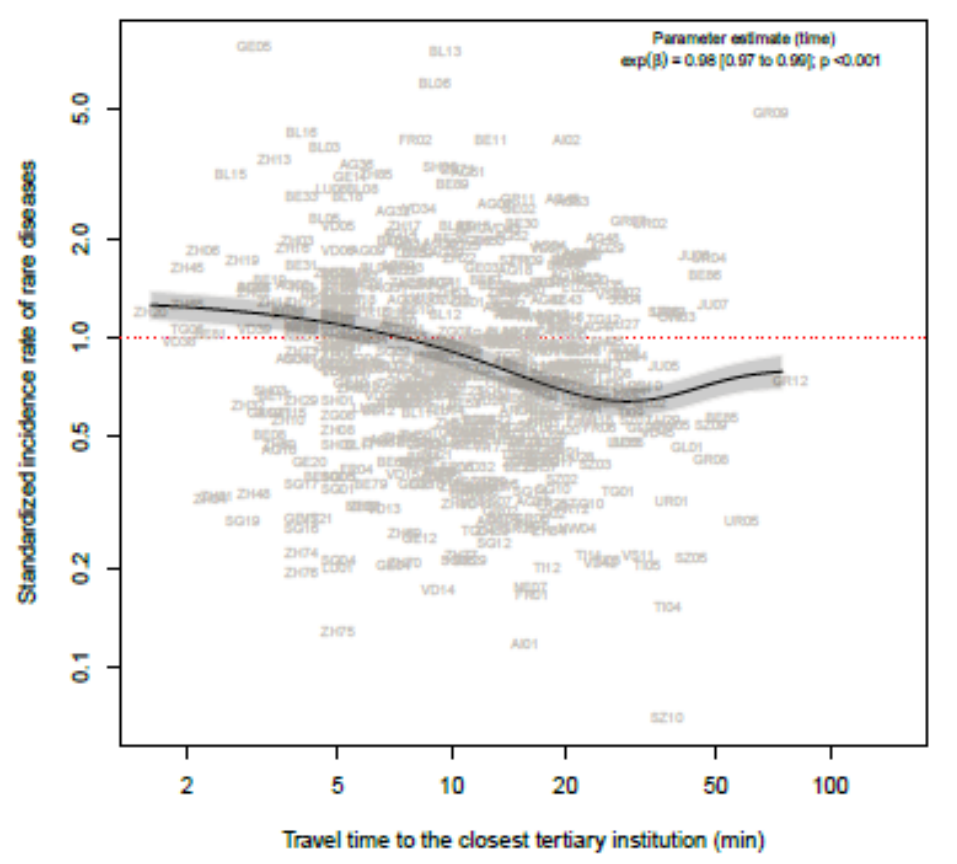

\section{Figure 2}

Correlation of the Diagnostic Diversity Index depending on residence and proximity to the next center. Panel A - Diagnostic diversity of inpatient cases living in a particular residential area in relation to travel time to the next tertiary hospital based on all inpatient cases overall ICD-10 codes shows a significant association with an inflection point at 21 minutes. For inpatient cases with travel times $>21$ minutes from their homes, a relevant proportional reduction of diagnostic diversity was found, typically below the mean hacalino of $\mathrm{h}$ a Danol R - rhlornnloth of tha Swiss national geographical distribution of diagnostic Loading [MathJax]/jax/output/CommonHTML/jax.js 
diversity of inpatient cases according to their Medstat-residential area and the location relative to the nearest tertiary inpatient facilities (small red dots; university hospitals large red dots). Medstat-regions, where residents reached a mean DDI for their inpatient cases $>6.9$, were marked in grey. Grey areas tend to co-localize with tertiary inpatient facilities. Panel $\mathrm{C}-$ Chloropleth of travel times from the individual Medstat-residential area to the next tertiary inpatient facility. Medstat-regions with a mean travel time $<21$ minutes to the next tertiary inpatient facility are shown in grey. Panel D - The standardized incidence rate of inpatient cases living in a particular residential area diagnosed with orphan diseases in relation to travel time to the next tertiary hospital shows a significant association with a lower incidence rate for orphan diseases in more remote residential areas.
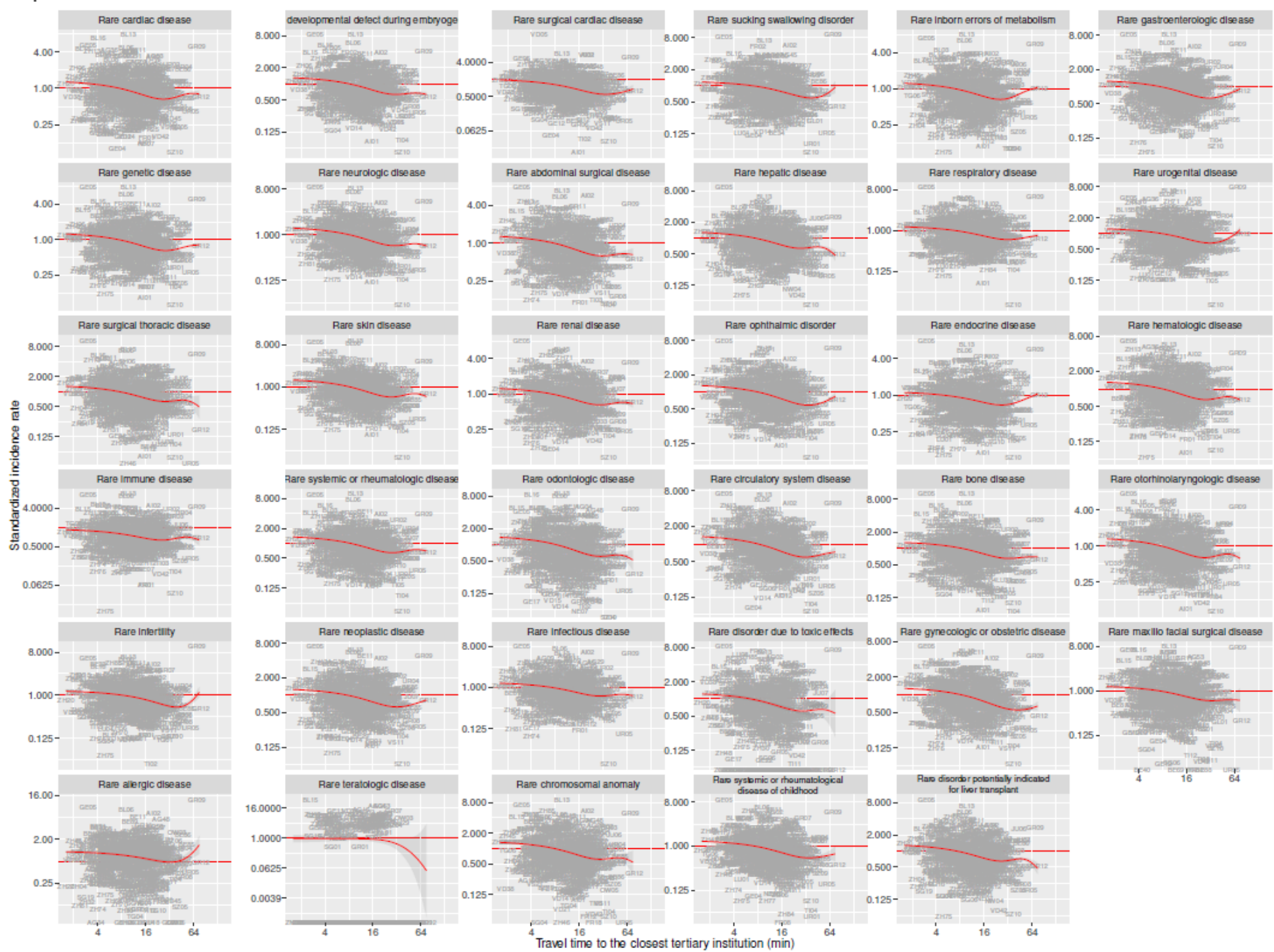

\section{Figure 3}

Standardized incidence of rare diseases related to travel time from residence to the next center. Overall significant associations between standardized incidence rates and travel times were observed for 33/35 chapters. The two exceptions were the rare disease groups "rare teratologic disease" and "rare allergic disease". 